\title{
DESIGN AND SIMULATION OF DUAL POLARIZED PATCH ANTENNA
}

\author{
B.M Sachin \\ Department of ECE \\ RV College of Engineering Bengaluru-560059, India \\ Dr. Shushrutha K.S \\ Department of ECE \\ RV College of Engineering Bengaluru-560059, India
}

\begin{abstract}
A single layer dual-polarized microstrip patch antenna with dual port is designed, simulated and analyzed. The two ports are provided with a $180^{\circ}$ phase shift and designed to operate in the C-band with a solution frequency at $4 \mathrm{GHz}$. The edges of the patch are etched which helps to improve the polarization of the designed antenna. The inset feed is the feeding technique used for the design of the dual-polarized antenna which provides a gain of about $8.5 \mathrm{~dB}$. This paper describes the parameters of the dual-polarized patch antenna like VSWR, Radiation Pattern, Axial Ratio and Return Loss are simulated and results are recorded. The proposed antenna works for the single narrow band frequency having a return loss lesser than $-10 \mathrm{~dB}$ and finds its application in satellite communications and weather RADAR.
\end{abstract}

Key words: Dual-polarized antenna, VSWR (Voltage Wave Standing Ratio), Axial Ratio, Phase shift, inset feed.

Cite this Article: B.M Sachin and Dr. Shushrutha K.S, Design and Simulation of Dual Polarized Patch Antenna, International Journal of Advanced Research in Engineering and Technology, 10 (4), 2019, pp 15-21.

$\mathrm{http}: / /$ iaeme.com/Home/issue/IJARET?Volume $=10 \&$ Issue $=4$

\section{INTRODUCION}

In the wireless communication systems, the dual-polarized microstrip antenna have a wide range of scope in the modern wireless systems. The microstrip patch antenna have many advantages like low weight, low cost, low profile, conformability and can be easily fabricated [1]. Thus microstrip patch antenna finds various applications due to which it opens a path to research field and many researches have been reported on it. The antennas are mainly characterized by some of its parameters like Gain, Return Loss of the antenna, Voltage Wave Standing Ratio (VSWR) of the antenna, Radiation patterns of the antenna and Axial Ratio Value. The micro-strip patch antennas due to its small size it can resonate at multiple frequency bands [2]. Dual-Polarized micro-strip patch antennas are mainly used to increase the performance of the system by polarizing the antenna at the base station. A good port 
isolation is necessary for a dual-polarized antenna to obtain the good frequency reuse communication while the antenna is transmitting or receiving the signal. There are many proposed designs to achieve a good port isolations between the ports to make the antenna dual-polarized [3].

The major drawback of the dual-polarized patch antenna is its limiting gain which narrows down the use of wireless applications. Hence, several ways like array configuring, introducing Lens of different dielectric material, introducing DRA (Dielectric Resonator Antenna) and so on can help in enhancing the gain of the dual-polarized antenna.

\section{DUAL-POLARIZED PATCH ANTENNA}

The Single band antenna introduction, dual-polarized antenna structure and its characteristics are discussed in this work. Analysis of antenna terminologies is discussed along with the advantages and limitations of single band and dual-polarized antenna. The IEEE Standard describes the antenna or aerial as "a means of transmitting or receiving electromagnetic waves or it can be said that the antenna is a transitional structure between guides and a free space [4]. To describe the dual-polarized antenna the following parameters are essential.

- Return Loss: The return loss is the signal power loss that is reflected back owing to a transmission line's discontinuity. The discontinuity can be corrected by inserting the device in the row or terminating the load. Usually the return loss value is displayed in $\mathrm{dB}$ [7].

- Radiation pattern: It is the radiated energy from the antenna represented by the radiating antenna's specific patterns. These models of radiation are the signal depictions that, as a function of direction, are the distribution of radiated energy into space.

- Gain: It is a metric which takes the antenna's effectiveness and directional capacities into consideration. The gain of an antenna (in a specified direction) is described as the proportion of strength to the radiation intensity that would be acquired if the energy adopted by the antenna were isotopic ally radiated.

- VSWR: Voltage Standing Wave Ratio is the coefficient of reflection feature that defines the antenna's reflected energy [5].

Few of the advantages of the dual-polarized antenna is as listed below:

- It decreases the signal interference [6].

- It has the capability to communicate with both horizontally and vertically polarized antennas.

- It reduces space as we don't require two separate antennas for different polarizations.

- It enables to decrease the expense of reducing the antenna size and improves system efficiency.

\section{ANTENNA DESIGN}

The proposed structure of the antenna is designed on a single layer Taconic substrate and a ground plane at the bottom which is also the same dimension of substrate. The geometry of the antenna is as shown in the figure1. 


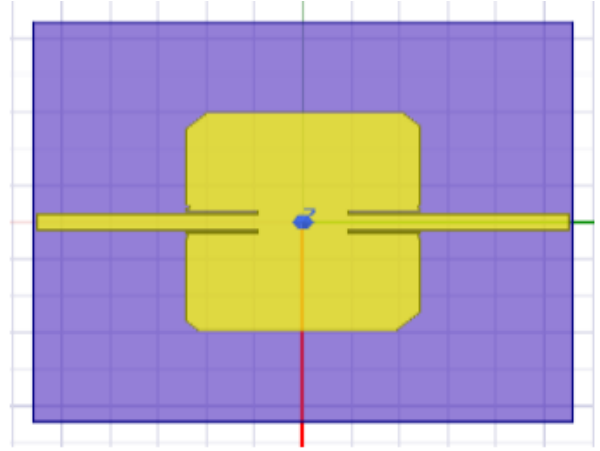

Figure 1 Top view of design proposed

As the dimension of the substrate on which the radiating patch is designed varies the antenna parameters very accordingly. The edges of the patch are etched to obtain the better polarization of the designed structure. The two ports are provided with $180^{\circ}$ phase shift and the patch antenna is exited with inset fed technique. The material chosen, its specifications like dielectric constant, loss tangent, Substrate thickness and dimensions of the substrate and the patch are as mentioned in the table 1.

Table 1 Material specifications and Dimensions of the Substrate and the Patch.

\begin{tabular}{|c|c|}
\hline Name of the Substrate & Taconic TLY \\
\hline Loss Tangent of the substrate & 0.0009 \\
\hline Dielectric constant of the substrate & 2.2 \\
\hline Thickness of the Substrate (in $\mathbf{m m}$ ) & 1.6 \\
\hline Dimension of the Substrate (in $\mathbf{m m}$ ) & $54 \times 56$ \\
\hline Patch dimension (in $\mathbf{m m})$ & $29.65 \times 24.4$ \\
\hline
\end{tabular}

The methodology of the design is explained in brief with the help of a flow chart. The Figure 2 shows the general steps involved starting from the design of the antenna to testing of the designed antenna. The proposed design can be further optimized to get the better axial ratio value by compromising the gain of the design. 


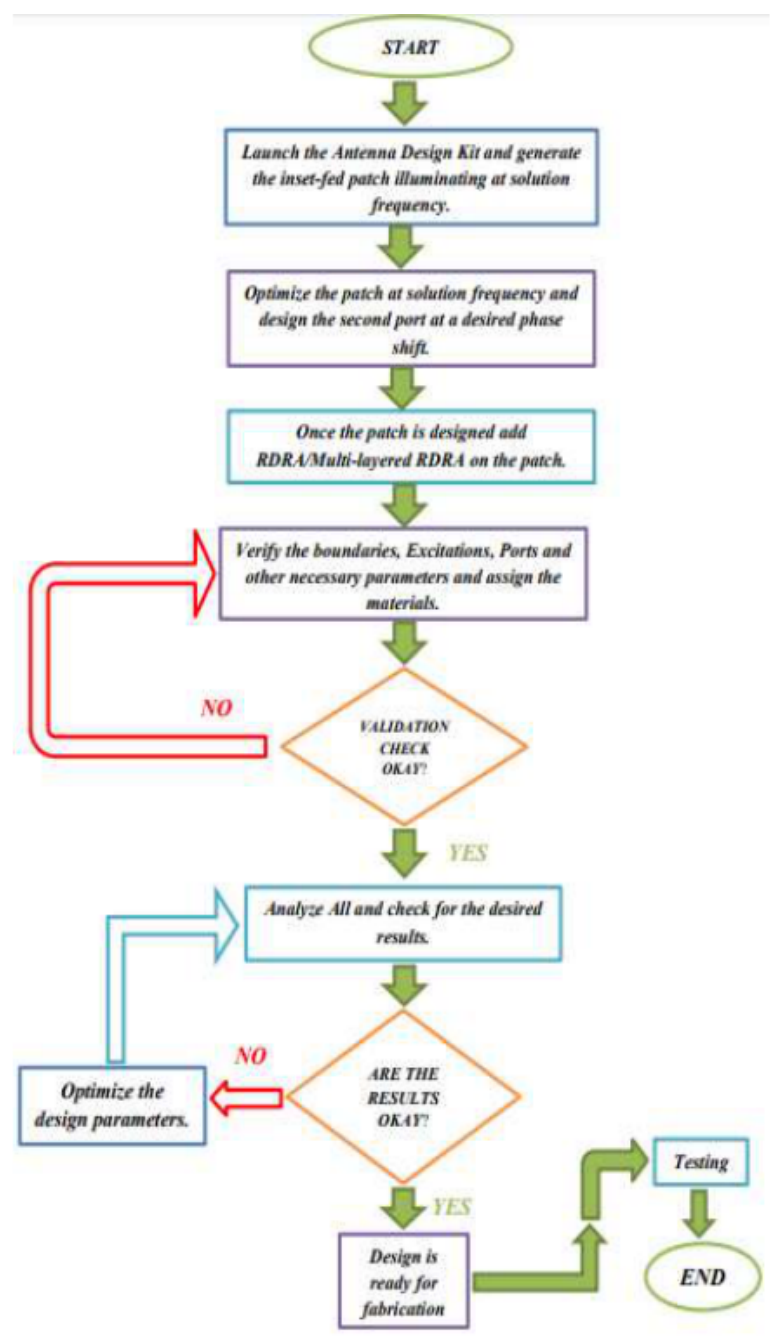

Figure 2 Flow chart of the methodology

\section{RESULTS AND DISCUSSION}

Dual-Polarized Patch Antenna simulation is performed using HFSS (High Frequency Structure Simulator), a software package to calculate a structure's electromagnetic conduct. Post processing instructions for evaluation are included in the software. To know the antenna is dual-polarized or not the parameters like VSWR and axial ratio are important. The software enables the user to draw the structure, specify the features of the fabric and recognize unique surface features.

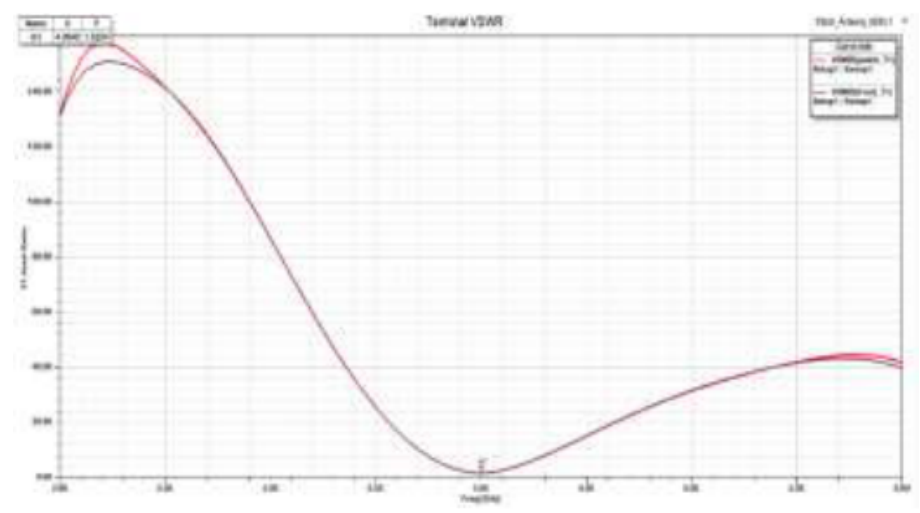

Figure 3 Frequency vs VSWR Plot 
The antenna is said to be dual-polarized when the VSWR value is less than 2 [6]. From above Figure 3, the VSWR obtained for the designed antenna at $4 \mathrm{GHz}$ is $1.5224 \mathrm{~dB}$. Figure 4 shows the radiation pattern of the dual polarized patch antenna intended for $4 \mathrm{GHz}$ solution frequency.
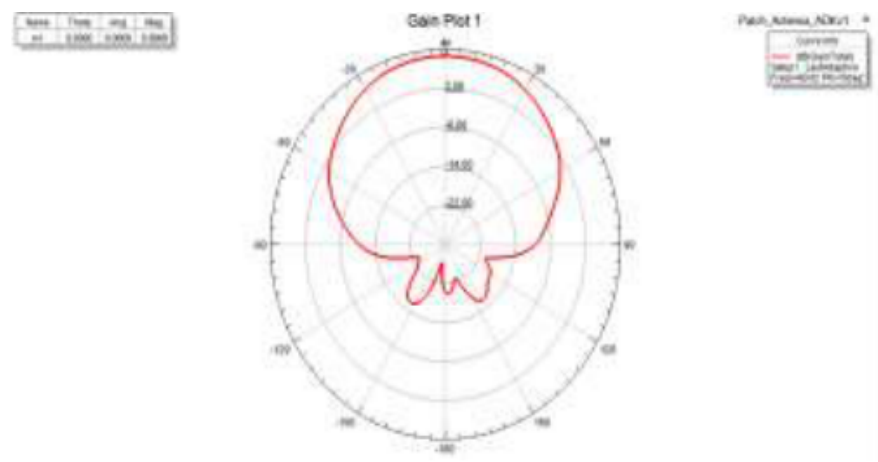

Figure 4 Frequency Vs VSWR Plot

The axial ratio is the proportion between the radiation pattern's minor and significant axis. It is said that the antenna is dual polarized if the antenna's axial ratio is less than $3 \mathrm{~dB}$. The axial ratio vs angle plot is shown in Figure 5.

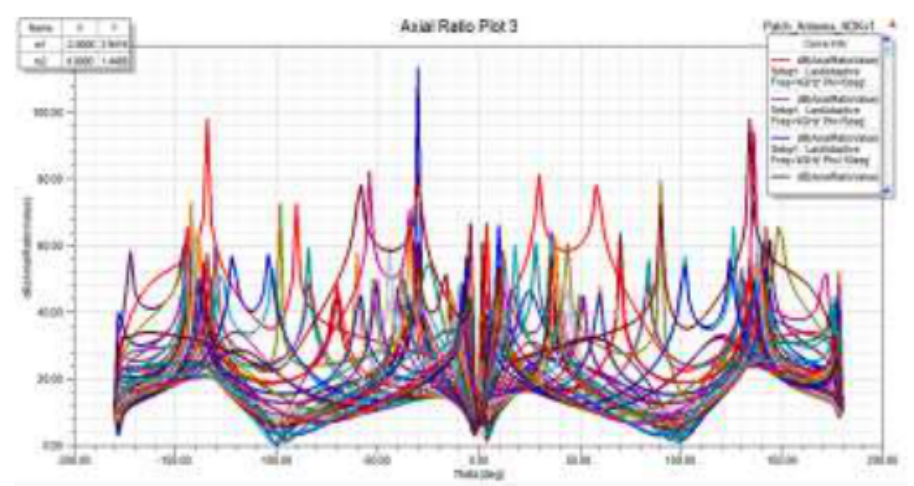

Figure 5 Theta (in degrees) Vs Axial Ratio Plot

At the angles $-2^{0}$ and $4^{0}$ the axial ratio value is found to be $2.9416 \mathrm{~dB}$ and $1.4482 \mathrm{~dB}$ respectively.

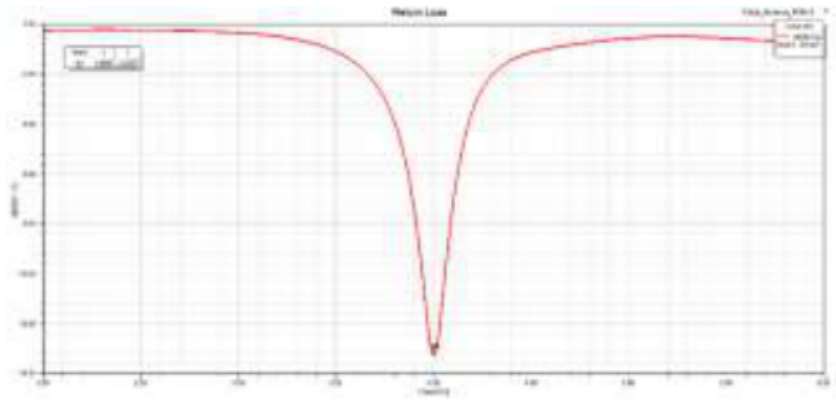

Figure 6 Simulated Return loss

The above Figure 6 demonstrates the Return Loss simulated. The return loss should be less than $-10 \mathrm{~dB}$ for a decent antenna layout. The return loss is discovered to be $-13.2227 \mathrm{~dB}$ in the suggested antenna design.

As shown in Table 2 below, the simulation outcomes of the dual-polarized patch for parameters such as VSWR, Radiation Pattern, Axial Ratio and 4GHz Return Loss are tabulated. 
Table 2 The simulation results of the parameters of the dual polarized antenna

\begin{tabular}{|l|c|}
\hline VSWR (in dB) & 1.5224 \\
\hline Radiation Pattern (in dB) & 8.5969 \\
\hline Axial Ratio Value at $-\mathbf{2}^{\mathbf{0}}$ and $\mathbf{4}^{\mathbf{0}}$ (in dB) & $2.9416,1.4482$ \\
\hline Return Loss (in dB) & -13.2227 \\
\hline
\end{tabular}

\section{FUTURE SCOPE AND CONCLUSION}

This paper defines the single layer dual port inset feed at $4 \mathrm{GHGz}$ illuminating dual-polarized patch antenna and the return loss is $-13.2227 \mathrm{~dB}$. Furthermore, the antenna gain can be improved by implementing various methods such as shell, lens and DRA, etc. The proposed design can be further more optimized and can be fabricated. This design finds its application in satellite communications, point to point communications such as in mobile communications and in weather RADAR's.

\section{REFERENCES}

[1] Yanshan Gou, Quanjiang Zhu, Shiwen Yang and Zaiping Nie, "A Compact Dual-Polarized DoubleShaped Patch Antenna with High Isolation”, IEEE Transactions on Antennas and Propagation, Volume: 61, Issue: 8, pp no.4349-4353, August 2013.

[2] H. Nornikman, B. H. Ahmad, M. R. M. Esa, M. R. Ahmad, M. Z. A. Abd Aziz, Z. Zakaria and C. S. Siang, "Dual Circular-Polarized Slot Antenna Design for Wireless MIMO System at 2.4 GHz", IEEE Conference on Electrical Engineering and Computer Science, pp no.19-23, January 2019.

[3] Uma Shankar Modani and Gajanand Jagrawal, A Slotted E-Shaped Stacked Layers Patch Antenna for 5.15-5.85 GHz Frequency Band Applications, International Journal of Electronics and Communication Engineering \& Technology (IJECET).Volume:4, Issue: 3, 2013, Pages: 11-23.

[4] S. Chatterjee and A Bhattacharya, Active Rectangular Patch Antenna - A New Design Philosophy, International Journal of Electronics and Communication Engineering \& Technology (IJECET).Volume:3, Issue: 1, 2012, Pages: 220-228.

[5] Arvind Singh Jadon, Jalaj Sharma, Ajay Prajapat and Avanish Bhadauria, Coplanar Rectangular Patch Antenna for X Band Applications Using Inset Fed Technique, International Journal of Electronics and Communication Engineering \& Technology (IJECET).Volume:4, Issue: 7, 2013, Pages: 95-102.

[6] S. Megha, C. Unni, N. A. Ali Fathima and N. Jayarenjini, "A Novel Microstrip Fractal Antenna with Dual Polarization.”, IEEE.Recent Advances in Intelligent Computational Systems (RAICS), pp no.7681, June 2016.

[7] Ayad Shohdy W. Ghattas and Elsayed Esam M. Khaled, a Compact Proximity-Fed Quad BandNotched Ultra-Wideband Patch Antenna. International Journal of Electronics and Communication Engineering \& Technology (IJECET). Volume:5, Issue: 1, 2014, Pages: 43-51.

[8] Constantine A. Balanis, “Antenna Theory Analysis and Design”, John Wiley \& Sons Publications, 3nd edition, 2014.

[9] Amit Kumar Gupta, R.K. Prasad, Dr. D.K. Srivastava, Design and Development of Dual E-Shaped Microstrippatch Antenna for Bandwidth and Gain Enhancement, International Journal of Electronics and Communication Engineering \& Technology (IJECET).Volume:3, Issue: 3, 2012, Pages: 34-42.

[10] Vidyadhar S Melkeri, S L Mallikarjun and P V Hunagund,H-Shape Defected Ground Structure (Dgs) Embedded Square Patch Antenna .International Journal of Advanced Research in Engineering and Technology (IJARET) .Volume: 6, Issue: 1, 2015, Pages: 76-83.

[11] Ros Marie C Cleetus and T.Sudha, Design and Analysis of a Frequency and Pattern Reconfigurable Microstrip Patch Antenna Using Various Electronic Switching Components, International Journal of Electronics and Communication Engineering \& Technology (IJECET).Volume:4, Issue: 4, 2013, Pages: 262-271.

[12] Mukul Jain and Sarika Jain, Design and Analysis of Pentagon Microstip Patch Antenna with Rectangular Slot for Wifi Backhaul Connectivity Application. International Journal of Electronics and Communication Engineering and Technology, 8(5), 2017, pp. 18-24. 
[13] G.A.Bidkar, P.V.Hunagund, R.M.Vani, S.N. Mulgi, P.M.Hadalgi, Low Cost Slotted Microstrip Line Fed Shorted Patch Antenna .International Journal of Electronics and Communication Engineering \& Technology (IJECET).Volume:2, Issue: 1, 2011, Pages: 11-16.

[14] Uma Shankar Modani and Gajanand Jagrawal, Microstrip Line Fed Stacked Layer E- Shaped Patch Antenna for Wlan and Wimax APPLICATIONS.International Journal of Electronics and Communication Engineering \& Technology (IJECET).Volume: 4, Issue: 3, 2013, Pages: 48-55.

[15] Dominic S. Nyitamen and Gabriel Ugalahi, Microstrip Patch Antenna for Improved Wi-Fi Reception. International Journal of Electronics and Communication Engineering and Technology, 9(5), 2018, pp. $17-26$.

[16] Dr. Nagraj K. Kulkarni, A Comparative Study of Various Patch Antennas for Wlan Applications.International Journal of Advanced Research in Engineering and Technology (IJARET) .Volume:5, Issue: 1, 2014, Pages: 182-186.

[17] Padmavathi C. Miniaturisation of Patch Antenna Using Novel Fractal Geometry. International Journal of Electronics and Communication Engineering \& Technology, 7(1), 2016, pp. 63-74.

[18] Oh Taeckkeun, Yeon-Geun Lim, Chan-Byoung Chae, and Yongshik Lee, "Dual-Polarization Slot Antenna with High Cross-Polarization Discrimination for Indoor Small-Cell MIMO Systems", IEEE Antennas and Wireless Propagation Letters 14 (2015), Volume: 14, pp no.374-77, October 2014.

[19] Vanishree S B, P.A.Ambresh, G.A.Bidkar, R.M.Vani, P.V. Hunagund, Novel Design of a Low Cost Microstripline-fed Shorted Patch Antenna for Communication Applications.International Journal of Electronics and Communication Engineering \& Technology (IJECET).Volume: 3, Issue: 3, 2012, Pages: 235-239.

[20] Roopan, Raveena Bhatoa and Ekambir Sidhu, Novel High Gain EbS Shaped Micro strip Patch Antenna Design Employing Fr4 Substrate for Radio Determination, Passive Sensors, Maritime Radar, Radiolocation (Military), Active Sensors, Altimeters, Scatter Meters, Precipitation Radars and Airborne Doppler Navigation Aids Applications. International Journal of Advanced Research in Engineering and Technology (IJARET) .Volume:8, Issue: 3, 2017, Pages: 50-55.

[21] Sankul Agarwal, Amandeep Singh, Rohit Jha and Rishabh Jain, 2013. Optimization of Rectangular Microstrip Patch Antenna Parameters in L Band by Employment of Proposed Composite Negative Index Metamaterial Structure .International Journal of Electronics and Communication Engineering \& Technology (IJECET).Volume:4, Issue: 4, Pages: 176-187.

[22] M L Meena and Mithilesh Kumar, Partially Hexagonal Ground Plane Uwb Elliptical Patch Antenna.International Journal of Electronics and Communication Engineering \& Technology (IJECET).Volume:4, Issue: 7, 2013, Pages: 66-73.

[23] K. Karuna Kumari and Dr. P.V.Sridevi, Performance Evaluation of Circular Micro strip Patch Antenna Array with Different Dielectric Substrate Materials, International Journal of Electronics and Communication Engineering \& Technology (IJECET).Volume:4, Issue: 1, 2013, Pages: 236-249.

[24] Tauheed Qamar, Naseem Halder, Mohd. Gulman Siddiqui, Vishal Varshney, Simulation And Analysis Of Slot-coupled Patch Antenna at Different Frequencies Using Hfss .International Journal of Electronics and Communication Engineering \& Technology (IJECET).Volume:3, Issue: 3, 2012, Pages: $1-7$.

[25] Jyotika Sawhney and Gurpreet Kumar, A Patch Antenna Loaded with Varactor for Multiband Operation using Fractals in Reconfigurable Antenna. International Journal of Electronics and Communication Engineering and Technology, 9(1), 2018, pp. 23-30.

[26] Ka Ming Mak. And Kwai Man LukRoger, "A Circularly Polarized Antenna with Wide Axial Ratio Beam width", IEEE Transactions on Antennas and Propagation, Volume: 57, Issue: 10, pp no. 33093312, August 2009.

[27] Anila Dhingra, Dr. K. C. Roy, Dr. O. S. Lamba and Govind Kumar, A Photonic Substrate U-Slot Dual Band Patch Antenna for UWB Applications, International Journal of Electronics and Communication Engineering and Technology, 7(6), 2016, pp. 25-31. 